\title{
Appendix Tubular Adenoma
}

National Cancer Institute

\section{Source}

National Cancer Institute. Appendix Tubular Adenoma. NCI Thesaurus. Code C43546.

An adenoma arising from the appendix. It is characterized by the presence of tubular epithelial structures and it is associated with dysplasia. 